\title{
Characterization of Lipopolysaccharides Isolated from Agrobacterium tumefaciens
}

\author{
By MIRJA SALKINOJA-SALONEN AND RIITTA BOECK \\ Department of General Microbiology, University of Helsinki, \\ Malminkatu 20, SF-00100 Helsinki 10, Finland
}

(Received 15 September 1977)

\begin{abstract}
Lipopolysaccharide (LPS) was isolated from two strains of Agrobacterium tumefaciens and analysed. It contained phosphate, hexose, hexosamine, fatty acids and 2-keto-3-deoxyoctonic acid. Of the compounds commonly found in LPS, heptose and galactosamine were absent. The fatty acid composition of the agrobacterial LPS is unique, since only 3-hydroxytetradecanoic acid and 3-hydroxyhexadecanoic acid were significant components. 3Hydroxyhexadecanoic acid was linked via an amide bond to the carbohydrate backbone. Non-hydroxylated fatty acids were present only as impurities $(<3 \%)$.
\end{abstract}

\section{INTRODUCTION}

The understanding of the mechanism of specific recognition between a plant cell wall and a bacterial surface has made considerable progress. Recent results (Wolpert \& Albersheim, 1976; Dazzo \& Hubbel, 1975) indicate that a lectin-type interaction of the legume plant cell surface with the $\mathrm{O}$-antigen of their specific rhizobia might be involved. The first step in the tumorigenesis by Agrobacterium of its target cells also probably involves specific recognition. Very little is known of its molecular mechanism. Since Rhizobium and Agrobacterium are closely related a kind of lectin-type interaction involving somatic antigens of the invading bacteria might not be unexpected.

The extracellular polysaccharides of both Rhizobium and Agrobacterium have been extensively studied (Björndal et al., 1971; Dundman, 1964; Humphrey \& Vincent, 1959) but little analytical work has been done on the lipopolysaccharide (LPS) of these genera. We describe here the isolation and chemical analysis of purified LPS from two crown gallforming strains of Agrobacterium tumefaciens. A preliminary report of this work has been presented (Salkinoja-Salonen \& Boeck, 1976).

\section{METHODS}

Bacterial cultures. Agrobacterium tumefaciens strains 0362 and TT111 were obtained from Professor J. de Ley, Laboratory of Microbiology and Microbial Genetics, State University, Gent, Belgium. They were maintained on slants containing $\left(\mathrm{g} \mathrm{l}^{-1}\right)$ : glucose, 10 ; yeast extract, $10 ;\left(\mathrm{NH}_{4}\right)_{2} \mathrm{SO}_{4}, 1 ; \mathrm{KH}_{2} \mathrm{PO}_{4}, 0.025 ;$ and agar, 15; the $\mathrm{pH}$ was 6.5. Salmonella typhimurium strains sL1181 and sH4247, used as reference strains, were obtained from Professor P. H. Mäkelä, Central Public Health Laboratory, Helsinki, Finland, and Pseudomonas aeruginosa strain PAC1 from Dr P. M. Meadow, Department of Biochemistry, University College London.

Isolation of LPS. The strains were grown in the medium described above (without agar) at $28^{\circ} \mathrm{C}$ in a 141 vessel of a laboratory fermenter (New Brunswick) with forced aeration (1 litre air per litre medium $\mathrm{min}^{-1}$ ) and agitation ( $200 \mathrm{rev} . \mathrm{min}^{-1}$ ). Cultures were harvested at a turbidity of 140 to 150 Klett units (filter 54) by centrifugation at $3000 \mathrm{~g}$ at $8{ }^{\circ} \mathrm{C}$ and the organisms were washed twice with $0.9 \%(\mathrm{w} / \mathrm{v}) \mathrm{NaCl}$. The amount of slime adhering to the cells was negligible. LPS was extracted from lyophilized cells by $45 \%(\mathrm{w} / \mathrm{v}) \mathrm{phenol}$ (strains Tr111, sH4247, sL1181, PAC1) as described by Westphal \& Jann (1965) and by $\mathrm{CHCl}_{3} /$ petroleum 
ether/phenol (strain 0362) as described by Galanos, Lüderitz \& Westphal (1969). The phenol was removed by extensive dialysis (four to six changes, $3 \times 24 \mathrm{~h}$ ). The solution was then concentrated 10-fold by rotary evaporation and centrifuged at $3000 \mathrm{rev} . \mathrm{min}^{-1}$ for $30 \mathrm{~min}$ to remove aggregates. The LPS was collected by centrifugation at $27000 \mathrm{rev} . \mathrm{min}^{-1}$ for $4 \mathrm{~h}$ in the SW27 rotor of a Spinco ultracentrifuge at $4{ }^{\circ} \mathrm{C}$.

Purification of agrobacterial LPS. The LPS was dissolved $\left(5\right.$ to $\left.10 \mathrm{mg} \mathrm{ml}^{-1}\right)$ in buffer $(10 \mathrm{~mm}-$ Tris $/ \mathrm{HCl}$, pH 7.6, $50 \mathrm{~mm}-\mathrm{KCl}, 10 \mathrm{~mm}$-magnesium acetate); deoxyribonuclease $\left(10 \mu \mathrm{g} \mathrm{ml}^{-1}\right)$, ribonuclease $\left(50 \mu \mathrm{g} \mathrm{ml}^{-1}\right)$ and lysozyme $\left(100 \mu \mathrm{g} \mathrm{ml}^{-1}\right)$ were added and the solution was incubated for $3 \mathrm{~h}$ at $37^{\circ} \mathrm{C}$. Chloroform $(5 \mathrm{vol}$.) and methanol $(8 \mathrm{vol}$.) were then added and the solution was vigorously mixed for $5 \mathrm{~s}$. After $1 \mathrm{~h}$ the mixture was centrifuged ( $20 \mathrm{~min} ; 2000 \mathrm{~g}$ ) and water $(3 \mathrm{vol}$.) and chloroform (11 vol.) were added to the supernatant. After mixing, the phases were separated by centrifugation $(10 \mathrm{~min} ; 1500 \mathrm{~g})$ and the organic phase was washed with $0 \cdot 2$ vol. of theoretical upper phase $\left(\mathrm{CHCl}_{3} / \mathrm{H}_{2} \mathrm{O} / \mathrm{CH}_{3} \mathrm{OH}, 3: 47: 48\right.$, by vol.). Organic solvents were removed from the combined water phases by evaporation to one-fifth of the original volume. Finally the LPS was collected by ultracentrifugation as above. The yield was approximately $100 \mathrm{mg}$ purified LPS for every $2 \mathrm{~g}$ dry cells.

Qualitative analyses. The LPS was hydrolysed for thin-layer chromatography of the sugars in $4 \mathrm{M}-\mathrm{HCl}$ at $100^{\circ} \mathrm{C}$ for $4 \mathrm{~h}$. Chromatograms prepared from LPS hydrolysed in $1 \mathrm{M}-\mathrm{HCl}$ instead of $4 \mathrm{M}-\mathrm{HCl}$ showed no new spots. Plates of Kieselgel 60 (Merck; $0.25 \mathrm{~mm}$ ) were sprayed with $0.05 \mathrm{M}-\mathrm{Na}_{2} \mathrm{~B}_{4} \mathrm{O}_{7}$ and activated at $115^{\circ} \mathrm{C}$ for $50 \mathrm{~min}$ before use. The chromatograms were developed twice for $11 \mathrm{~cm}$ in 1-propanol/water $(70: 20, v / v)$ and stained with the diphenylamine reagent no. 12 (Stahl, 1967). The sugars were identified by comparison with standard compounds and with LPS preparations of known sugar compositions (S. typhimurium sH4247, sL1181, P. aegurinosa PAC1).

Quantitative analyses. Samples were digested in $\mathrm{H}_{2} \mathrm{SO}_{4} / \mathrm{H}_{2} \mathrm{O}_{2}$ and their phosphorus content was measured by the method of Bartlett (1959). 2-Keto-3-deoxyoctonate (KDO) was determined as described by Osborn (1963), and rhamnose and heptose by the method of Dische (1963) using D-manno-heptulose (Sigma) and L-rhamnose (Fluka, Buchs, Switzerland) as standards. Glucose was determined by the glucose oxidase test (Boehringer) after hydrolysis in $1 \mathrm{M}-\mathrm{HCl}\left(100^{\circ} \mathrm{C} ; 4 \mathrm{~h}\right)$. Amino sugars were analysed after hydrolysis in $6 \cdot 1 \mathrm{M}-\mathrm{HCl}\left(105^{\circ} \mathrm{C} ; 4 \mathrm{~h}\right)$ using an automatic analyser as described by Chester, Meadow \& Pitt (1973). Hexosamine content was also determined colorimetrically (Rondle \& Morgan, 1955), and hexoses by the anthrone reaction (Keleti \& Lederer, 1974). The amount of fatty acids was determined both colorimetrically (Itaya \& Ui, 1965) and by gas-liquid chromatography (see below).

Fatty acid analyses. Methyl esters of the following fatty acids were used as reference compounds: dodecanoic, tetradecanoic, hexadecanoic (all from Merck), heptadecanoic and octadecanoic acids (both from Roth, Karlsruhe, F.R.G.); 3-hydroxydodecanoic, 3-hydroxytetradecanoic and 3-hydroxyhexadecanoic acids (all from Applied Science Laboratories); 2-hydroxytetradecanoic acid (Fluka) and 2-hydroxyhexadecanoic acid (Koch-Light); and a mixture of branched (both iso and anteiso) chain fatty acid methyl esters (BC-mix L, Applied Science Laboratories). Identification of $\Delta^{2}$ - and $\Delta^{3}$-unsaturated fatty acids and 3-methoxytetradecanoic acid was based on the retention time data of these compounds (E. T. Rietschel, personal communication). Fatty acids were liberated from the LPS by alkaline hydrolysis $\left(4 \mathrm{M}-\mathrm{KOH} ; 5 \mathrm{~h} ; 100^{\circ} \mathrm{C}\right)$ or by methanolysis in sulphuric acid/methanol $\left(6: 94, \mathrm{v} / \mathrm{v} ; 70^{\circ} \mathrm{C} ; 6 \mathrm{~h}\right)$. Ester-bound acids were converted into methyl esters by transesterification in $0.25 \mathrm{M}-\mathrm{NaOCH}_{3}$ in methanol as described by Rietschel et al. (1972). The amidelinked fatty acids were identified by alkaline hydrolysis $\left(4 \mathrm{M}-\mathrm{KOH} ; 5 \mathrm{~h} ; 100^{\circ} \mathrm{C}\right)$ of the diethyl ether-insoluble residue obtained after the transesterification. Free fatty acids were carbomethylated with diazomethane in diethyl ether (Schlenk \& Gellerman, 1960). Hydroxy fatty acids were separated from the non-polar fatty acids by thin-layer chromatography at $37^{\circ} \mathrm{C}$ on Kieselgel $\mathrm{G}$ (Merck; $0.25 \mathrm{~mm}$ ) using ethyl acetate/chloroform $(1: 4, \mathrm{v} / \mathrm{v} ; 7 \mathrm{~cm})$ and then benzene $(14 \mathrm{~cm})$ as solvents. The spots were visualized by spraying with fluorescein $(0.05 \%, \mathrm{w} / \mathrm{v}$, in ethanol), scraped off, extracted with $4 \times 4 \mathrm{ml}$ chloroform/methanol $(2: 1, \mathrm{v} / \mathrm{v})$ in an ultrasonic bath and analysed by gas-liquid chromatography (g.l.c.).

Gas-liquid chromatography. Fatty acid methyl esters were separated on two different columns of stainless steel $(2 \mathrm{~mm} \times 200 \mathrm{~cm})$ : EGSS-X $(10 \%$ on Gas Chrom P, $100 / 120 \mathrm{mesh})$ at $165^{\circ} \mathrm{C}$ and SE-30 $(3 \%$ on Gas Chrom Q, 80/100 mesh) at $180^{\circ} \mathrm{C}$. A Perkin-Elmer gas chromatograph F11 equipped with a flame ionization detector was used. Nitrogen $\left(30 \mathrm{ml} \mathrm{min}{ }^{-1}\right)$ was used as carrier gas and heptadecanoic acid methyl ester was used as an internal reference for the quantitative determination of the fatty acids. The amounts of individual fatty acids present were calculated from the chromatograms obtained on the EGSS-X columns.

\section{RESULTS}

Purity of LPS preparations

We used the phenol/water procedure of Westphal \& Jann (1965) for the first extraction of LPS. For strain 0362, the modified petroleum ether/chloroform/phenol extraction 
Table 1. Composition of lipopolysaccharides isolated from strains 0362 and TT111 of Agrobacterium tumefaciens

\begin{tabular}{|c|c|c|c|}
\hline & \multicolumn{3}{|c|}{ Amount recovered $\left[\mathrm{mg}(\mathrm{g} \mathrm{LPS})^{-1}\right]$} \\
\hline & Strain ... $0362(\mathrm{I})^{*}$ & $0362(\mathrm{II})^{*}$ & TT111 \\
\hline Fatty acid (colorimetric) $\dagger$ & 203 & & 119 \\
\hline Fatty acid (g.l.c.) $\ddagger$ & 95 & 108 & 64 \\
\hline Phosphorus & 28 & 25 & 55 \\
\hline Hexose§ & 193 & 170 & 181 \\
\hline Hexosamine || & 126 & 118 & 82 \\
\hline KDO & 59 & 53 & 12 \\
\hline Heptose & 0 & 0 & 0 \\
\hline
\end{tabular}

* Different LPS preparations from strain 0362.

$\uparrow$ Measured by the method of Itaya \& Ui (1965), using a standard curve prepared with palmitic acid.

\# Sum of the peak areas in the gas-liquid chromatogram (EGSS-X column) of LPS hydrolysed in $4 \mathrm{M}-$ $\mathrm{KOH}\left(5 \mathrm{~h} ; 100^{\circ} \mathrm{C}\right)$, with $n$-heptadecanoic acid as internal standard.

$\S$ Total hexose content determined colorimetrically by the anthrone method.

If Total hexosamine content determined colorimetrically by the method of Rondle \& Morgan (1955).

procedure of Galanos et al. (1969) gave a better yield, though the colony morphologies of the two A. tumefaciens strains are similar.

When the isolated products were screened for amino compounds in the amino acid analyser, glucosamine and glucosamine phosphate were found together with substantial amounts (10 to $70 \mu \mathrm{g} \mathrm{mg}^{-1}$ ) of alanine, glutamic acid, glycine and substances whose peaks coincided with those for muramic acid and diaminopimelic acid. It was concluded that the product was contaminated with murein. Digestion with lysozyme removed all of the amino acid peaks from the analyser spectrum and was subsequently used routinely.

\section{Chemical composition of LPS preparations}

Table 1 shows the quantities of fatty acid, phosphorus, hexosamine, KDO and hexoses recovered from purified LPS of strains 0362 and TT111 of $A$. tumefaciens. The material is of true glycolipid nature, for $6 \%$ (TT111) and 10\% (0362) of it is fatty acid. The colorimetric method gave a higher value for the fatty acid content than did the g.l.c. method. The reason for this discrepancy remains unknown. Fatty acid, phosphorus, hexose, hexosamine and KDO together represented about $50 \%(\mathrm{w} / \mathrm{w})$ of the purified LPS. No heptose was found. This absence was verified by running parallel analyses in which heptose $\left(50 \mu \mathrm{g} \mathrm{mg}^{-1}\right)$ or LPS of $S$. typhimurium SH4247 (known to contain $0.20 \mu \mathrm{mol}^{2}$ heptose $\mathrm{mg}^{-1}$ ) was mixed with the agrobacterial LPS. The measurement of heptose gave the expected results, hence the negative results with the agrobacterial LPS cannot be due to the presence of components which interfere with the estimation of heptose.

\section{Sugar analysis of LPS preparations}

A qualitative pattern of the sugar content of the LPS preparations was obtained by thinlayer chromatography on plates pre-impregnated with sodium tetraborate. In this way a sharp separation was obtained for a large number of sugars on a single run, including the three epimeric hexoses (glucose, galactose and mannose). The chromatographic separation of sugars gave the same five major spots for the LPS of strains TT111 and 0362 of A. tumefaciens, namely galactose, glucose, mannose, rhamnose and glucosamine. In addition, faint spots were seen which had the same apparent $R_{F}$, but not the colour, of spots from standard fucose and xylose.

The amount of glucose in all LPS preparations was about $1 \%(\mathrm{w} / \mathrm{w})($ Table 2$)$. The amount of rhamnose, however, varied considerably from one preparation to another and 
Table 2. Amounts of glucose, rhamnose and amino sugars in lipopolysaccharides isolated from strains 0362 and TT111 of Agrobacterium tumefaciens

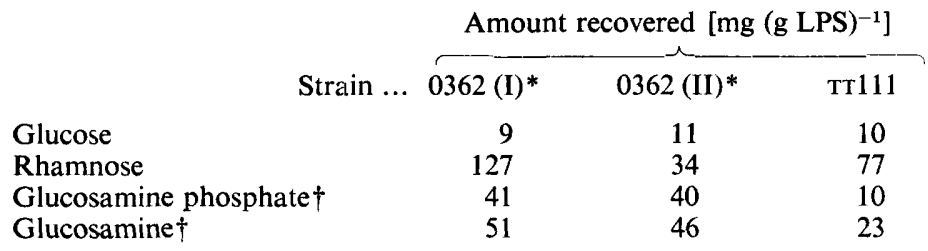

* Different LPS preparations from strain 0362.

$\uparrow$ Calculated from results obtained with the amino acid analyser.

Table 3. Retention times and amounts of fatty acids found in cells and LPS of Agrobacterium tumefaciens after hydrolysis in $4 \mathrm{M}-\mathrm{KOH}$ for $5 \mathrm{~h}$ at $100{ }^{\circ} \mathrm{C}$

\begin{tabular}{|c|c|c|c|c|c|}
\hline & \multirow{3}{*}{$\begin{array}{c}\text { Relative } \\
\text { retention } \\
\text { time* }\end{array}$} & \multicolumn{4}{|c|}{ Amount recovered [mg ( $\mathrm{g}$ cells or LPS $)^{-1}$ ] } \\
\hline & & \multicolumn{2}{|c|}{ Strain 0362} & \multicolumn{2}{|c|}{ Strain $\Upsilon \mathrm{T} 111$} \\
\hline & & Cells & LPS & Cells & LPS \\
\hline Tetradecanoic & $0 \cdot 38$ & 1 & 0 & $<1$ & 0 \\
\hline 3-OH-Tetradecanoic & $2 \cdot 45$ & $5 \cdot 2$ & 71 & $2 \cdot 6$ & 49 \\
\hline Hexadecanoic & 0.73 & $4 \cdot 5$ & 0 & $2 \cdot 5$ & 0 \\
\hline 3-OH-Hexadecanoic & $4 \cdot 60$ & 1.9 & $22 \cdot 2$ & 0.6 & $14 \cdot 9$ \\
\hline$\Delta^{9}$-Hexadecenoic & 0.87 & 1.4 & 0 & $1 \cdot 7$ & 0 \\
\hline Octadecanoic & $1 \cdot 37$ & $0 \cdot 4$ & $2 \cdot 3$ & $<1$ & 0 \\
\hline$\Delta^{11}$-Octadecenoic & 1.66 & 50 & 0 & $28 \cdot 4$ & $1 \cdot 0$ \\
\hline Other & & 1 & $<0.5$ & 1 & $<0.5$ \\
\hline
\end{tabular}

* Retention time of methyl ester on g.l.c. (EGSS-X column; $165^{\circ} \mathrm{C}$ ) relative to heptadecanoic acid methyl ester $(=1 \cdot 00)$.

also within a single strain. Analyses of preparations from strain 0362 with high and low contents of rhamnose (I and II in Tables 1 and 2) showed that such variation did not occur in other constituents of LPS.

The only amino compounds detected by automated amino compound analysis of the pure LPS product after hydrolysis in $6.1 \mathrm{M}-\mathrm{HCl}$ (see Table 2) were glucosamine phosphate and glucosamine. From the LPS of strain 0362, the amount of glucosamine plus glucosamine phosphate recovered approached the amount found by the method of Rondle \& Morgan (1955). From the LPS of strain TT111, less than one-half of the 'Rondle \& Morgan hexosamine' was recovered by the amino acid analyser in the form of glucosamine plus glucosamine phosphate. Instead, a large amount of amino compounds was eluted from the ion exchange resin in the final $\mathrm{NaOH}$ wash. This was not seen with the LPS of strain 0362 or with other LPS materials which were analysed. Therefore, the LPS of strain TT111 may contain labile amino compounds destroyed by the conditions used for hydrolysis in the present experiments.

\section{Fatty acid analysis of LPS preparations}

Fatty acids in the agrobacterial LPS preparations were identified by comparing their retention times with those of the reference compounds on two columns having different separation properties. The LPS of both strains of $A$. tumefaciens contained only 3-hydroxytetradecanoic acid and 3-hydroxyhexadecanoic acid, in a ratio of 3:1 (Table 3). Cisvaccenic acid ( $\Delta^{11}$-octadecenoic acid) which predominates in the cellular lipids, constituting approximately $80 \%$ of all fatty acid present, was virtually absent in the LPS. About $20 \%$ of the fatty acids of crude LPS was found to be cis-vaccenic acid but this was removed by extraction with chloroform/methanol. Very little hydroxy acid, if any, was removed by such 
(a)

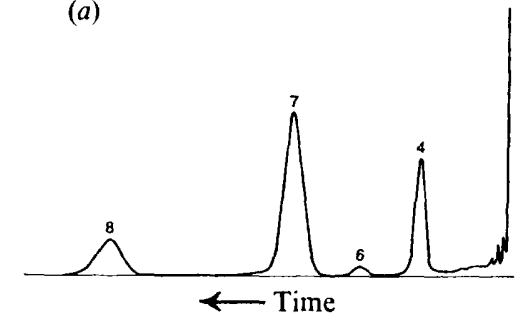

(b)

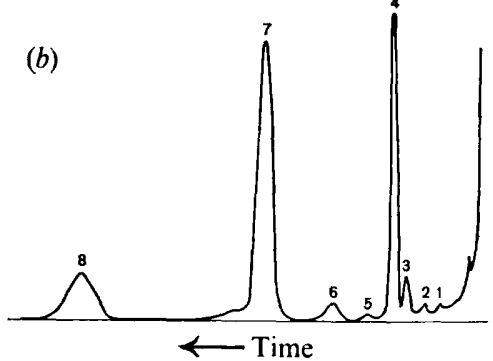

Fig. 1. Gas-liquid chromatograms (EGSS-X column; $165^{\circ} \mathrm{C}$ ) of methyl esters of fatty acids released from purified LPS of strain 0362 of $A$. tumefaciens by $(a)$ direct methanolysis and $(b)$ alkaline hydrolysis $(4 \mathrm{M}-\mathrm{KOH})$. The peaks correspond to (1) $\Delta^{3}$-tetradecenoic, (2) $\Delta^{2}$-tetradecenoic, (3) 3- $\mathrm{OCH}_{3}$-tetradecanoic, (4) heptadecanoic, used as internal reference, (5) $\Delta^{2}$-hexadecenoic, (6) 3- $\mathrm{OCH}_{3}$-hexadecanoic and $\Delta^{11}$-octadecenoic, (7) 3-OH-tetradecanoic and (8) 3-OH-hexadecanoic acid.

an extraction. We therefore conclude that $c i s$-vaccenic acid is not covalently bound to the LPS.

The identity of the fatty acids recovered from the agrobacterial LPS was confirmed by separation of the polar and the non-polar fatty acid methyl esters by thin-layer chromatography. The methyl esters were extracted from the spots on the silica gel plate and reanalysed by g.l.c. Both of the major peaks in the LPS chromatograms were found to have comigrated with the authentic 3-hydroxytetradecanoic and 3-hydroxyhexadecanoic acids. We thus conclude that there are no non-polar fatty acids in the LPS of strains 0362 and TT111 of A. tumefaciens.

Alkaline hydrolysis of the agrobacterial LPS yielded the same major fatty acids as did direct methanolysis with sulphuric acid/methanol (Fig. 1 $a, b$ ). The peaks present in Fig. 1(b) but not in Fig. 1(a) have retention times similar to those of $\Delta^{2}$-tetradecenoic acid, $\Delta^{3}$ tetradecenoic acid, 3-methoxytetradecanoic acid and $\Delta^{2}$-hexadecenoic acid. These compounds can be expected to arise from chemical modification of the respective 3-hydroxy acids during alkaline hydrolysis (Rietschel, Lüderitz \& Volk, 1975). The occurrence of these artefacts thus confirms the identification of the two major peaks as 3-hydroxytetradecanoic and 3-hydroxyhexadecanoic acid.

\section{Linkage of fatty acids to LPS}

Ester-bound fatty acids are liberated from LPS by $\mathrm{NaOCH}_{3}$ (Rietschel et al., 1972). When the LPS of strains 0362 and TT111 were subjected to transmethylation in $0.25 \mathrm{M}-\mathrm{NaOCH}$ in methanol, over $90 \%$ of the 3-hydroxytetradecanoic acid was released but none of the 3-hydroxyhexadecanoic acid. When the de-acylated ether-insoluble residue obtained after transmethylation in $0.25 \mathrm{M}-\mathrm{NaOCH}_{3}$ was digested in strong alkali and carbomethylated with diazomethane, only one major peak, that for the 3-hydroxyhexadecanoic acid, was found by subsequent g.l.c. analysis. This means that only the 3-hydroxyhexadecanoic acid is linked via amino groups to the carbohydrate backbone in the agrobacterial LPS.

\section{DISCUSSION}

Although the structure of the O-side chains of LPS is greatly diversified, the core region is similar for large groups of bacteria (for review, see Galanos et al., 1977). Common components of the LPS core are KDO, heptose, phosphate, non-polar and 3-hydroxy fatty acids, glucosamine, galactosamine and hexoses. The LPS of $A$. tumefaciens also contains these compounds except for heptose, galactosamine and non-polar fatty acid. The hexoses found were glucose, galactose, mannose and rhamnose. No attempt was made to isolate and analyse the core separately from the total LPS. 
Graham \& O'Brien (1968) isolated and analysed qualitatively the sugars and amino sugars of LPS of Rhizobium and Agrobacterium including six strains of $A$. tumefaciens. They reported the same sugars for $A$. tumefaciens as we have found and, in addition, fucose or $O$-methylglucuronic acid in some of the strains. Heptose was absent. Our results thus confirm those of Graham \& O'Brien although we used different strains whose relatedness to theirs is not known. The species $A$. tumefaciens includes a wide variety of Gram-negative rods which, in some cases, have tumorigenicity towards plants as the only common property (Kersters et al., 1973; Lippincott \& Lippincott, 1975).

We know of no previous report on the fatty acids of the LPS of $A$. tumefaciens. Rhizobial LPS has been reported to contain 3-hydroxytetradecanoic, 3-hydroxyhexadecanoic, 3hydroxyoctadecanoic and hexadecanoic acids (Russa \& Lorkiewicz, 1974, 1976). Such long-chain hydroxy fatty acids have also been reported in a number of phylogenetically unrelated bacteria including Coxiella burneti (Chan, McChesney \& Paretsky, 1976), Fusobacterium nucleatum (Hase, Hofstad \& Rietschel, 1977) and the blue-green alga Anabaena variabilis (Weckesser et al., 1974).

A distinctive feature of the LPS of $A$.tumefaciens is the fact that it contains hydroxylated fatty acids only. In the LPS of the species mentioned above, the hydroxy fatty acids usually account for less than $50 \%$ of the total fatty acids although the LPS of Rhizobium trifolii has an unusually high hydroxy fatty acid content, i.e. $70 \%$ of the total (Russa \& Lorkiewicz, 1974). It is tempting to expect correlation between this unusual feature of the LPS of $A$. tumefaciens and $R$. trifolii and their unique ability to adhere specifically to plant ceil walls in the infection process leading to tumour (nodule) production. However, more strains of Rhizobium and Agrobacterium need to be studied before conclusions can be drawn.

This work was supported financially by the Academy of Finland and by Suomalainen Tiedeakatemia. The authors thank Mr Peter Laverack (Department of Biochemistry, University College London) for performing the amino acid analyses and Dr E. T. Rietschel for critically reading the manuscript.

\section{REFERENCES}

Bartlett, G. R. (1959). Phosphorus assay in column chromatography. Journal of Biological Chemistry 234, 466-468.

Björndal, K., ERbing, O., Lindberg, B., Fahraeus, G. \& LJungren, H. (1971). Studies on an extracellular polysaccharide from Rhizobium meliloti. Acta chemica scandinavica 25, 1281-1286.

Chan, M. L., McChesney, J. \& Paretsky, D. (1976). Further characterization of a lipopolysaccharide from Coxiella burneti. Infection and Immunity 13, 1721-1727.

Chester, I. R., Meadow, P. M. \& Pitt, T. L. (1973). The relationship between the O-antigenic lipopolysaccharides and serological specificity in strains of Pseudomonas aeruginosa of different O-serotypes. Journal of General Microbiology 78, 305-318.

Dazzo, F. B. \& Hubbel, D. H. (1975). Cross-reactive antigens and lectin as determinants of symbiotic specificity in the Rhizobium-clover association. Applied Microbiology 30, 1017-1033.

Dische, Z. (1963). Colour reactions of carbohydrates. Methods in Carbohydrate Chemistry 1, 501.

Dundman, W. F. (1964). Growth and extracellular polysaccharide production by Rhizobium meliloti in defined medium. Journal of Bacteriology 88, 640-645.

Galanos, C., Lüderitz, O. \& WestPhal, O. (1969). A new method for the extraction of $\mathbf{R}$ lipopolysaccharides. European Journal of Biochemistry 9, 245-249.

Galanos, C., Lüderitz, O., Rietschel, E. T. \& Westrial, O. (1977). Newer aspects of the chemistry and biology of bacterial lipopolysaccharides, with special reference to their lipid A component. In International Review of Biochemistry, Biochemistry of Lipids II, vol. 14, pp. 239-335. Edited by T. W. Goodwin. Baltimore: University Park Press.

Graham, P. H. \& O'Brien, M. A. (1968). Composition of lipopolysaccharides from Rhizobium and Agrobacterium. Antonie van Leeuwenhoek 34, 326-330.

Hase, S., Hofstad, T. \& Rietschel, E. T. (1977). Chemical structure of the lipid A component of lipopolysaccharides from Fusobacterium nucleatum. Journal of Bacteriology 129, 9-14.

Humphrey, B. A. \& Vincent, J. M. (1959). EXtracellular polysaccharides of Rhizobium. Journal of General Microbiology 21, 277-284. 
ITAYA, K. \& UI, M. (1965). Colorimetric determination of free fatty acids in biological fluids. Journal of Lipid Research 6, 16-20.

Keleti, G. \& Lederer, W. H. (editors) (1974). Handbook of Micromethods for the Biological Sciences, pp. 73-74. New York: Van Nostrand Reinhold Co.

Kersters, K., De Ley, J., Sneath, P. H. A. \& SACKIN, M. (1973). Numerical taxonomic analysis of Agrobacterium. Journal of General Microbiology 78, 227-239.

LippincotT, J. A. \& LippincotT, B. B. (1975). The genus Agrobacterium and plant tumorigenesis. Annual Review of Microbiology 29, 377-405.

OsBorN, M. J. (1963). Studies on the Gram-negative cell wall. I. Evidence for the role of 2-keto-3deoxyoctonate in the lipopolysaccharide of Salmonella typhimurium. Proceedings of the National Academy of Sciences of the United States of America 50, 499-506.

Rietschel, E., GotTert, H., Lüderitz, O. \& WeSTPHAL, O. (1972). Nature and linkages of the fatty acids present in the lipid A component of Salmonella lipopolysaccharides. European Journal of Biochemistry 28, 166-173.

Rietschel, E., Lüderitz, O. \& VolK, W. (1975). Nature, type of linkage and absolute configuration of (hydroxy) fatty acids in lipopolysaccharides from Xanthomonas sinensis and related strains. Journal of Bacteriology 122, 1180-1188.

Rondle, C. J. M. \& Morgan, W. T. J. (1955). Determination of glucosamine and galactosamine. Biochemical Journal 61, 586-589.
Russa, R. \& LoRkiewicz, Z. (1974). Fatty acids present in the lipopolysaccharide of Rhizobium trifolii. Journal of Bacteriology 119, 771-775.

RusSA, R. \& LoRKIEwICZ, Z. (1976). Hydroksykwasy jako skladniki lipopolisacharydow Rhizobium. Polskie Towarzystwo Biochemiczne XIV Zjazd, p. 233.

Salkinoja-Salonen, M. \& Boeck, R. (1976). The composition of agrobacterial lipopolysaccharides. Abstracts of the 8th Meeting of the North West European Microbiological Group, Helsinki 1976, p. 150.

Schlenk, H. \& Gellerman, I. L. (1960). Esterification of fatty acids with diazomethane on a small scale. Analytical Chemistry 32, 1412-1414.

Stahl, E. (1967). Dünnschicht-Chromatographie. Berlin: Springer Verlag.

Weckesser, J., Katz, A., Drews, G., Mayer, H. \& Fromme, I. (1974). Lipopolysaccharide containing $\mathrm{L}$-acofriose in the filamentous blue-green alga Anabaena variabilis. Journal of Bacteriology 120, 672-678.

WeSTPHAL, O. \& JANN, O. (1965). Bacterial lipopolysaccharides. Methods in Carbohydrate Chemistry 5, 83-91.

Wolpert, J. S. \& Albersheim, P. (1976). Hostsymbiont interactions I. The lectins of legumes interact with the O-antigen-containing lipopolysaccharides of their symbiont rhizobia. Biochemical and Biophysical Research Communications 70, 729-737. 